\title{
Precinct scale living laboratories: Case study of Randwick Living lab
}

\author{
Eline Punt ${ }^{1 *}$, Aida Afrooz ${ }^{2}$, and Chris Pettit ${ }^{3}$ \\ ${ }^{1}$ Department of Human Geography and Spatial Planning, Faculty of Geosciences, Utrecht University, Utrecht, the Netherlands - \\ e.p.punt@uu.nl \\ ${ }^{2}$ School of Art, Architecture and Design, University of South Australia, IVE: Australian Research Centre for Interactive and Virtual \\ Environments, SA, 5000, Australia - aida.eslamiafrooz@unisa.edu.au \\ ${ }^{3}$ Faculty of the Built Environment, The University of New South Wales, Sydney, Australia - c.pettit@unsw.edu.au
}

Commission IV

KEY WORDS: living laboratories, user-centric design, data driven approaches, smart precincts, sketch planning

\begin{abstract}
:
The concept of Living Laboratory (LL) provides a novel grass-roots data-driven approach for collaborative design of place involving multiple stakeholders. In this paper we focused on reviewing the most common approaches utilised in the construct of user-centric LL. This is done by systematically reviewing methodologies and engagement techniques as well as presenting one LL milieu as a case study - Randwick Precinct Living Laboratory - and its key outcomes. In the case study we aimed to understand the design of a usercentric precinct scale LL where stakeholders were involved in the design of a precinct using a sketch planning approach. The novelty of the Randwick Precinct LL was the use of multi-table technologies and other digital planning tools such as a dashboard to support collaboration. The results suggest a sketch planning approach to facilitate and encourage both user-to-user and user-to-technology interaction and make the LL concept operate at precinct level. Moreover, this paper distils the lessons learned from Randwick Precinct Living Lab and explained how LL can contribute to inclusiveness, user contribution, high innovation, collaboration and consensus building.
\end{abstract}

\section{INTRODUCTION}

Generally Living laboratories (LL) can be seen as a form of open innovation or experimental governance in which innovations are developed in an open, inclusive and collaborative setting by engaging various stakeholders, including public or private organisations, universities and citizens (Chronéer et al. 2019; Voytenko et al. 2016). Voytenko et al. ( 2016) argue that despite many LLs emerging as a form of experimental governance, there is no clear understanding of their role in sustainable or smart urban development, whether they represent a completely new phenomenon, why funding agencies are investing in operationalising the LL concept, and the potential impacts of LLs. Additionally, there is no consensus on the main characteristics of an LL, or if they can be interpreted as an approach, single project or specific place (Chronéer et al. 2019). As a result, there is a need to clarify what characterises a LL (Chronéer et al. 2019; Voytenko et al. 2016). However, there is limited literature and reports available on LLs regarding their results, methods, and tools. Part of this lack of literature is due to the sensitivity of data and information being used at LLs.

In this paper we focus on the implementation of the concept of a living lab (LL) at the precinct level in Sydney metropolitan area. This paper has two parts. In the first part, we focus on reviewing current LL approaches. We focus, in particular, on active user involvement - which is a fundamental dimension to co-creation (Knight-Davidson et al. 2020) - and the inclusion of digital planning and design tools to determine if LLs are replacing other forms of participation, collaboration, experimentation, learning and governance. The aim of this part is to find and critically reflect on the most common approaches being utilised in creating user-centric LLs in a systematic review.

In the second part, we present a case study. This section of the paper summarises and discusses the results from the Randwick precinct LL co-design experiment undertaken on the $30^{\text {th }}$ August 2018. This paper built upon the results from our previous study on the Randwick precinct LL (Afrooz et al. 2018a). The aim of this project was to understand the design of a smart precinct LL. In particular this project aimed to understand how to make the LL concept operate at the precinct scale and to create a future vision of the LL in enabling meaningful innovations in response to sustainability challenges and the development of smart cities. The LL approach in this project allowed the development and examining of the LL concept by exploring partnership opportunities between stakeholders in the precinct, using data driven sketch planning inherent within the geodesign approach (Pettit et al. 2019b)and by providing a collaborative, innovative setting using the City Analytics Lab for the LL experiment (Punt et al. 2020). Sketch planning can be defined as the exploration of the planning problem at the early stages of the collaborative planning process where maps and drawing equipment is used to visualize views and ideas (Vonk and Ligtenberg 2010).

In this paper we focus on one LL milieu - Randwick precinct LL - and compare it to the most common approaches found in the literature to reflect on its strengths and weaknesses in relation to LL components.

Accordingly, section 2, reviews the literature on available methodologies, tools and engagement techniques for creating user-centric LL. Section 3 presents the Randwick precinct LL case study. Section 4 discusses the case study and compares it to the most common LL approaches found in the literature. Finally, the authors reflect on the strength and weakness of the LL approach used in the case study.

\footnotetext{
* Corresponding author
} 


\section{LITERATURE REVIEW}

\subsection{Living lab}

Pioneering LL activities took place primarily in the US, before transitioning into more practical applications in Europe (Leminen et al. 2017). Since then LLs have become prominent and novel forms of open innovation (Leminen et al. 2017). They have been reviewed from different approaches including environment (Schaffers et al. 2007), methodology (Eriksson, M., V.P. Niitamo, and S. Kulkki 2005), and a system (Corelabs 2007). Depending on the approach one uses, different themes come into focus (Bergvall-Kareborn and Stahlbrost 2009). The environment approach, for instance, highlights the role of objects such as technological platforms and user communities in shaping the LL environment (Bergvall-Kareborn and Stahlbrost 2009). Most important in this approach is the role of technology and physical lab space in creating interactions between users. Within the methodology approach data transfers and methods for user involvement come to forefront (Bergvall-Kareborn and Stahlbrost 2009).

Besides the traditional living lab, the concept of an urban living lab has surfaced in recent years. In an urban living lab, the city is viewed as a living laboratory where citizens and other stakeholders are actively involved in the process of designing, developing, implementing, testing and evaluating an innovation (Cosgrave et al. 2013; Chronéer et al. 2019; Veeckman and van der Graaf 2015). The terms living laboratory (LL) and urban living laboratory (ULL) are often used interchangeably and both have grown in popularity in an era of smart cities and digitisation. Bergvall-Kareborn and Stahlbrost (2009) defined five components for LLs including: end-users, application environments (i.e. the context in which users interact and reflect on the real world's usage scenario), technology and infrastructure (i.e. roles that new and existing ICT technologies can play to facilitate cooperating innovations between stakeholders), organisation, methods (i.e. methods that emerged as best practices), and partners. The cases study in this paper included all the above-mentioned components.

\subsection{Living lab approaches}

In this section, we reviewed the literature and noted most common methods and tools utilized in user-centric LLs. The two main sources considered were: 1) existing literature on the topic, and 2) web sources of existing examples of user-centric LLs. The examples are from both reviewed literature and practical case studies around the globe. The rest of this section describes the reviewed literature in Table 1.

A relatively traditional approach for analysing user-centric LL is taken by Park et al. (2018) and Romero Herrera (2017) who both used a combination of in-situ (i.e. capture contextual factors) and mixed methods (i.e. combination of quantitative and qualitative methods to capture technical and social aspects) to study different cases. Park et al. (2018) analysed three US/UK workplace sustainable LLs that implemented human and environmental sustainability futures into their office spaces. A novel method named a "lab in a bag" was used to study the changes in environmental quality. The lab consisted of a bag full of sensors that measured temperature, humidity, illumination, sound and electricity consumption. This bag was sent to the LLs and monitored environmental conditions continuously for two weeks pre- and post-move. This method was then complimented by two surveys that assessed participants' responses to the change in environmental conditions. Aspects recorded in these surveys were for example thermal, visual and auditory sensations, mood, level of focus, environmental satisfaction, attitudes and values regarding job performance and workplace culture, productivity measures and subjective physical and mental health. Preliminary analysis indicated that environmental sensations can be linked to employees' level of focus and mood, but that the visual and auditory sensations were not necessarily linked to sensor data. Romero Herrera (2017) focused on introducing innovative sustainable solutions in LLs. The sustainability LL offered a collaborative platform where experts with different expertise work together to generate sustainable solutions. Romero Herrera (2017) believed that the key part of this process is the "... integration of users' experiences and sustainability impact of their practices around technology appropriation" (p.9). Technology appropriation refers to a process of adopting the technology to fit users' lifestyle (Dourish 2003). Romero Herrera (2017) introduced three levels of integration each addressing different needs of the professionals and future users. She suggested in-situ and mixed methods to capture technical and social aspects of sustainable LLs.

Alternatively, some studies have used social media as a platform for user-centric LL approaches. For example, Finnigan, S.M., Clear, A.K. (2018) suggested a novel approach to LL engagement by tweeting smart buildings through which changes can be suggested by occupants and then implemented by building management. They combined social media-based interaction with LL-based building data to examine a newly built university building at Newcastle University which was designed as a LL space. They found potential to engage occupants and management in their negotiation process. Rather than collecting feedback from users using common quantitative methods such as surveys or questionnaires, Finnigan, S.M., Clear, A.K. (2018) used a Spacebot - a Twitter bot with a forum for occupant discussion. They develop a social media-based LL called UXModeler, which provided a digital space for user-centric design and engineering.

Some studies adopted comparative case studies analyses to study user-centred and participatory design approaches to LL. Almirall and Wareham (2011) performed a comparative case analysis of four working LLs to identify their common functions and how they aim to capture and incorporate the contribution of users in the innovation process. They found that the LL was operated by involving users in explorative processes in real-life environments and actively involving stakeholders in a process of learning and co-creation.

In another study Franz et al. (2015) compared three LL case studies to create a contextualized methodology by considering LL as a tool. They focused on the approaches to co-creation in LLs. The first case dealt with the involvement of residents in an impact analysis of local integration policies. The second case implemented and evaluated pervasive citizen participation, and the third case involved co-creators for urban mobility solutions through combining social and economic (technological) innovations.

Additionally, Schuurman et al. (2015) assessed relationships between user characteristics and user contributions for three case studies. In the first case study named "iCinema", they invited stakeholders from the movie industry to explore interactive cinema formats. Schuurman et al. (2015) divided participants into two different groups of: a) homogeneous users with high technical knowledge, and b) mixed group with high technical knowledge versus high user knowledge. Their results show that participants with similar amounts of knowledge (i.e. first group) were able to more profoundly discuss and ideate. However, the mixed group were more likely to come to a consensus (Schuurman et al. 2015).

The studies above all performed a comparative case study analysis of LLs in different ways. Almirall and Wareham (2011) chose a set of LL approaches carried out by one organisation in 
order to compare them. Franz et al. (2015) took a different approach. They applied a comparative case study on three divergent LL approaches and found that contextualizing LLs and embedding their innovation in appropriate, social, and institutional frameworks and targeting civil society involvement were important attributes of LL for smart planning practices. Finally, Schuurman et al. (2015) focussed on users' skills and knowledge rather than innovation or sets of practices. This approach is useful when the focus is on the benefits of a variety of users in one group. All the reviewed studies imply that the utilised LL approach need to be tailored for each individual case with an understanding of the setting and group of users. Since LL can mean a diversity of practices, organisations and projects with varying levels of maturity, it can be difficult to perform comparative analysis between LLs (Almirall and Wareham 2011).

Finally, Robust (2019a, 2019b, 2019c) also studied user-centred and participatory design methodologies based on a case study.
They used participatory spatial data analysis and co-design approaches with the aim of introducing innovative quantitative methods of measuring and evaluating socio-economic development at a small spatial scale to project partners. Participatory spatial data analysis is a method of jointly collecting, interpreting, and analysing data with the goal that respondents are actively involved in the analysis and interpretation of findings at all phases of the research cycle. Methods that were applied by Robust (2019c) included descriptive analysis, spatial autocorrelation and different procedures of spatial regression. In addition, this LL used a World Café methodology that ensured all participants got the opportunity to discuss themes including policy, education, and partnership, and participatory-design (Robust 2019a). The LL was ultimately used to co-create a vision for the Lisbon Metropolitan Area (Robust 2019b)

Table 1. Most common LL approaches

\begin{tabular}{|c|c|c|c|}
\hline Author & Category & Aim & LL approach/characteristics \\
\hline $\begin{array}{l}\text { (Almirall and Wareham } \\
\text { 2011) }\end{array}$ & $\begin{array}{l}\text { Comparative case } \\
\text { study: User-centred \& } \\
\text { participatory design }\end{array}$ & $\begin{array}{l}\text { Identify common functions of } \\
\text { LL through comparative case } \\
\text { study analysis }\end{array}$ & $\begin{array}{l}\text { LL incorporate user-based } \\
\text { experimentation and engage stakeholders } \\
\text { in a process of learning and co-creation }\end{array}$ \\
\hline $\begin{array}{l}\text { (Finnigan, S.M., Clear, } \\
\text { A.K. 2018) }\end{array}$ & Social-media analysis & $\begin{array}{l}\text { Design social-media concept to } \\
\text { co-create and evaluate LL } \\
\text { spaces }\end{array}$ & $\begin{array}{l}\text { Community engagement through social } \\
\text { media-based interaction in negotiation } \\
\text { processes }\end{array}$ \\
\hline (Franz et al. 2015) & $\begin{array}{l}\text { Comparative case } \\
\text { study: User-centred \& } \\
\text { participatory design }\end{array}$ & $\begin{array}{l}\text { Identify common functions of } \\
\text { LL through comparative case } \\
\text { study analysis }\end{array}$ & Co-creation and user-involvement \\
\hline (Karaseva et al. 2015) & Social media analysis & $\begin{array}{l}\text { Identify how stakeholders can } \\
\text { meet (in an online setting) }\end{array}$ & $\begin{array}{l}\text { Collaboration between stakeholders in } \\
\text { online meeting space }\end{array}$ \\
\hline (Park et al. 2018) & $\begin{array}{l}\text { In-situ, mixed methods } \\
\text { study }\end{array}$ & $\begin{array}{l}\text { Study participant response to } \\
\text { changes in environmental } \\
\text { quality }\end{array}$ & $\begin{array}{l}\text { Neutral thermal and visual sensations } \\
\text { create pleasant LL environment }\end{array}$ \\
\hline $\begin{array}{l}\text { (Robust 2019a, 2019b, } \\
\text { 2019c) }\end{array}$ & $\begin{array}{l}\text { User-centred \& } \\
\text { participatory design }\end{array}$ & $\begin{array}{l}\text { Identify how LL can be used to } \\
\text { co-create a vision for the Lisbon } \\
\text { Metropolitan Area }\end{array}$ & $\begin{array}{l}\text { Cultivation of open innovation and critical } \\
\text { thinking; co-creation, World Café } \\
\text { methodology to measure and evaluate } \\
\text { socio-economic development }\end{array}$ \\
\hline (Romero Herrera 2017) & $\begin{array}{l}\text { In-situ, mixed methods } \\
\text { study }\end{array}$ & $\begin{array}{l}\text { Introduced integrated approach } \\
\text { based on in-situ and mixed } \\
\text { methods }\end{array}$ & Three levels of user integration \\
\hline (Schuurman et al. 2015) & $\begin{array}{l}\text { Comparative case } \\
\text { study: User-centred \& } \\
\text { participatory design }\end{array}$ & $\begin{array}{l}\text { Assessed user characteristics } \\
\text { and their relation to } \\
\text { user contribution to co-creation } \\
\text { in LLs }\end{array}$ & User interaction \\
\hline
\end{tabular}

\subsection{Common Living Lab approaches}

Based on the previous section we identified different approaches utilised in user-centric LLs.

\subsubsection{Questionnaire, interviews, and focus groups}

Questionnaires and interviews have traditionally been used to identify consumer needs (Dell'Era and Landoni 2014). Questionnaires and interviews can be a good way to learn about users' perceptions on changes to the environment particularly for user-centric LLs. The reviewed literature showed that both Park et al. (2018) and Romero Herrera (2017) applied a combination of these methods in their studies. Alternatively, a focus group methodology can also be applied, which can collect complex information at low cost and minimum amount of time (Liamputtong 2011). Participants in a focus group must be a representative sample of users (Dell'Era and Landoni 2014).

\subsubsection{In-situ methods}

In-situ methods aim to capture an overview of daily life practices, generating knowledge that is bounded to temporal and contextual factors (Romero Herrera 2017). They can be used to gather insights on social practices, social networks, user behaviour, and experiences. Park et al. (2018) have used a form of in-situ methodology in their study by using technology (Lab in a Bag) 
to measure changes in the environment of the LLs and matching these changes to user experiences. Other in-situ methods include Experience Sampling Method (ESM) and Daily Reconstruction Method (DRM) that connect user experiences and practices to real contexts (Romero Herrera 2017).

\subsubsection{Social media}

A new method to improve user engagement, empowerment and participation is to use social media as a platform for data collection and analysis. For example, Finnigan, S.M., Clear, A.K. (2018) combined social media-based interactions with LL-based building data to reach a larger audience for engagement in negotiation processes (Karaseva et al. 2015), in another study, they used social media to bridge the gap between end-users, stakeholders, academic researchers, designers and service developers by providing a digital meeting space to create innovative services together.

\subsubsection{User-centred and participatory design approaches}

Three last categories we identified in the LL literature were usercentred, co-design and participatory design approaches. Robust (Robust 2019a, 2019b, 2019c) used three different approaches of user-centred and participatory design in their case study, including participatory co-design, participatory spatial data analysis and world café methodology. Almirall and Wareham (2011) found that LL observe user-led practice in diffuse social contexts to identify and codify tacit and practice-based knowledge and that LL diffuse this knowledge into ad hoc innovation networks. Schuurman et al. (2015) found that cocreation in LL sessions can yield to more diverse results and innovation-related knowledge and Franz et al. (2015) found that co-creation and user-involvement can be considered as key elements of LL designs.

Participatory design attempts to actively involve all stakeholders in the design process to ensure the product meets their needs (Dell'Era and Landoni 2014). Part of this approach is also codesign, where participants design the project together with researchers. In this process, participants cooperate with researchers, and developers during an innovation process (Dell'Era and Landoni 2014). From the reviewed literature, we noticed that the role of digital planning tools that can improve codesign approaches by improving the interaction between user-totechnology is missing in most studies. For example, while Almirall and Wareham (2011) and Schuurman et al. (2015) reviewed user contributions and user interactions in different case studies, neither included the role that digital tools can play in improving user contributions and interactions. This gap in the literature has been addressed in the Randwick Precinct case study by integrating and adapting an array of sketch planning tools with the aim of improving user-technology and user-user interaction.

\section{METHODOLOGY}

We conducted a case study of an experimental LL called Randwick precinct LL (Afrooz et al. 2018a). Case study research is a qualitative research methodology most suitable for a comprehensive, in-depth investigation of a complex issue in context, where the boundary between the context and issue is unclear and contains many variables (Harrison et al. 2017). Since living labs are complex and can be applied in various contexts, a case study analysis is often seen as the most appropriate method to provide a better understanding of living labs (Franz et al. 2015). This is also a method frequently found in the LL approaches reviewed in the previous section (See Table 1).

In this case study we utilised questionnaire and participatory data driven codesign approaches. The LL focused on the role of spatial information in supporting smart precinct planning and design, with real users and user needs, in a real-world context. The emphasis was on the design and redevelopment of a precinct in Randwick City Council situated within the Greater Metropolitan Sydney. This case entailed the redevelopment of the Randwick hospital campus. The precinct is identified as an area with high potential to grow into a centre of increased productivity and innovation (Afrooz et al. 2018a). Infrastructure developers, local and state government, industry, academia, community and other stakeholders explored the collaborative design and redevelopment of the Randwick precinct, using the LL mechanism that allowed organisations to work together in a technical and socially integrated environment to create placebased solutions to complex planning and infrastructure.

\subsection{City Analytics Lab}

CAL is a dedicated immersive space designed to support collaborative planning and user-centred design through a suite of digital sketch planning tools. Such immersive, smart labs have the potential to support the real-life simulation of city environments in LL and contribute to the adoption of proposed ideas and solutions by users or stakeholders (Dupont et al. 2016; Dupont et al. 2017). CAL consists of a planning support theater, which is equipped with six high-resolution multi-touch tables on which various planning support tools can be loaded, three Virtual Reality (VR)/Augmented Reality (AR) rooms, an Augmented Reality (AR) Sandbox and observation rooms for conducting experiments. Cruiser software was installed on all multi-touch tables, which allowed for data to be visualized, manipulated, and communicated (Cruiser Interactive 2019) CAL's primary goal was to support data augmented or sketch planning and design through the support of analytics, models, visualisations, and dashboards (Punt et al. 2020).

Two of the underlying design thinking methods supported in CAL were geodesign and data analytics. The geodesign framework proposed a number of critical questions, data and metrics that were ultimately meant to create and evaluate sustainable urban futures (Pettit et al. 2019a; Pettit et al. 2019b). Additionally, data analysis and visualisation tools in the lab including CityViz, a data visualisation and analytics platform, CityData, City Dashboard, a value uplift tool Rapid Analytics Interactive Scenario Explorer (RAISE), and the AR sandbox which was used to model and design new landscapes were continuously developed and applied to support evidence-based decision making and smart planning (Afrooz et al. 2018b; Goodspeed et al. 2017; Lieske et al. 2019; Pettit et al. 2017a; Pettit et al. 2017b; Punt et al. 2020).

CAL provides a collaborative space that promotes user-to-user and user-to-technology interactions in the formulation and evaluation of future city scenarios by allowing users to swipe and share digital artifacts between tables. As a result, this is an ideal facility for hosting a LL. CAL can support up to 40 stakeholders to unite and co-create and codesign services, systems, technologies and social solutions to real-life problems, in realworld settings assisted through a suite of digital planning and design tools.

\subsection{Participants}

Thirty-one participants took part in the case study. Participants ranged from a variety of organisations including universities, local governments, consulting engineering services, and government sectors with different expertise including: city planning, engineering, business, sustainability, ICT and GIS. Most of the participants had background knowledge on spatial planning and the design of Randwick precinct and they were informed prior to the LL session on topics, including smart cities, 
infrastructure, 3D spatial supporting precinct design and planning and living labs by presentations from experts (Afrooz et al. 2018a). However, only 12 participants (39\%) had previously used digital tools like interactive tables in this type of settings. This suggests that the use of interactive tables in LL is a relatively new concept.

\subsection{Procedure and tasks}

The Randwick precinct LL had two parts: design and implementation. The first part was performed at the CAL using the multi-touch interactive tables and the digital sketch planning tools. The second part was conducted in a neared by meeting room space design to support more traditional collaborative discussions. In part 1 (Design) participants were divided into five equal groups of 6 people. They were given 20 minutes and asked to a) spatially identify potential opportunities for the precinct, b) provide suggestions regarding the required data sets and, c) benchmark measures for monitoring the performance of the precinct using the planning support theatre, including multitouch tables at the CAL. Each group was given a specific theme to focus including (i) movement, (ii) infrastructure, (iii) liveability, (iv) productivity and (v) sustainability. See Figure 1 for an impression of the first part of the LL, where participants worked with the theme movement on the multi-touch tables. Participants utilised the multi-touch tables at the CAL which were equipped with Cruiser software. The Cruiser software allowed participants to undertake a sketch planning approach draw and visualise their ideas on a map, take notes, screenshots and use access the suite of digital planning tools, including visualisation tools such as the 30-minute city interactive map and a dashboard tool which provides travel time estimates to the Randwick Precinct (see Figure 2). Data gathered by the five groups on the multi-touch tables was exported and analysed. The ideas from the five different themes were combined into one map (See Figure 3) in order to visualise all generated ideas. At the end of the first part each group presented their visions using the multi-touch tables.

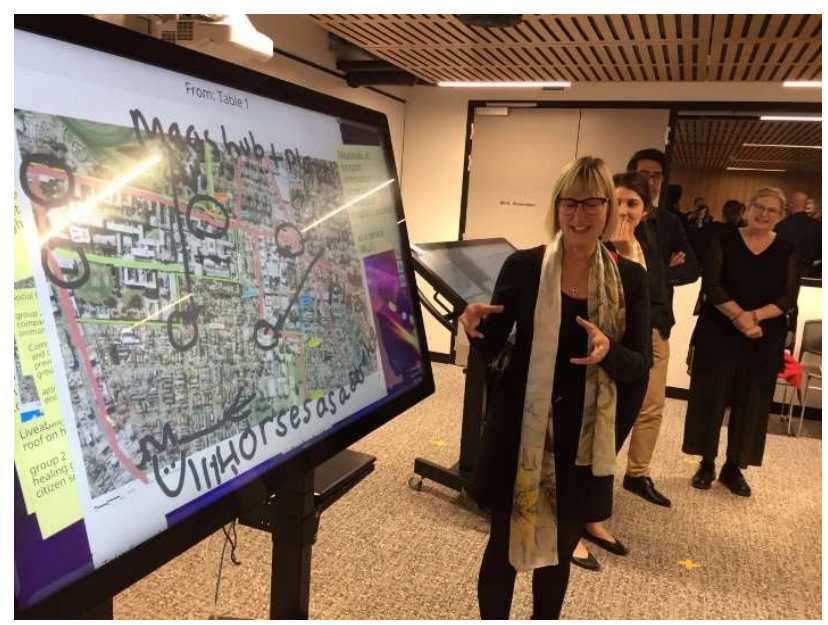

Figure 1 Multi-touch tables in action during the Randwick LL

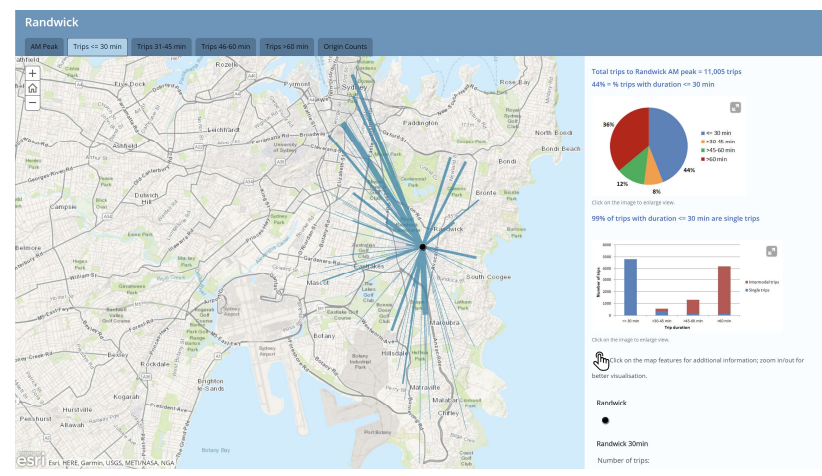

Figure 230 Minute City interactive Dashboard - Randwick precinct (https://cityfutures.be.unsw.edu.au/cityviz/- accessed 10/07/2020)

In part 2 (Implementation) participants were asked to consider the possible means of implementing their vision. Each group was then asked to brainstorm potential programs and initiatives, funding sources, project partners and stakeholders guided by four questions:

- Who are the stakeholders?

- How can we encourage collaboration and partnership?

- How can we attract new investment and funding?

- What are the measures of success?

This second part of the LL focused on a group ideation session and was held in a different codesign space near CAL to undertake a facilitated discussion. Participants were asked to use paper postit notes and chart papers to capture their ideas. Physical tools were used in this session to compare the experience of using this approach compared to a digital approach. The goal was to map key stakeholders and determine key measures of success for the future of the Randwick Precinct such as reduced travel time to the Precinct, increase active transport infrastructure, and increased community engagement with the University campus. Each group was given 20 minutes to complete the task and 2 minutes to negotiate their ideas with other groups.

After the LL, an evaluation survey was conducted with the dual purpose of (i) ascertaining the usability of the CAL to support the LL, (ii) capture the reflection of participants on the opportunities for the Randwick precinct LL. The results from this survey are discussed in the next section.

\section{RESULTS}

In this section we discuss the outcomes of the Randwick precinct LL. This case study is then compared with the reviewed approaches to reflect on the strengths and weaknesses of usercentric and data-driven LL approach.

As outlined in the previous section, in part 1 participants were asked to brainstorm ideas on how to improve the Randwick precinct based on the five themes. These considerations were brought together onto a digital map and included: electro micro grids for green energy, street lighting to improve safety liveability and Mobility as a Service (MaaS) hubs to support active transport into the precinct (see Figure 3). This was used as a basis for creating and implementing a LL smart and sustainable vision for a smart Randwick Precinct.

Next, participants were asked to rank the top three opportunities to understand the place-based design opportunities for the Randwick precinct LL based on the findings from part 1 . The results were:

Improvements to the flow of transport by introducing an east-west light rail and a bicycle corridor with opportunities for active transport, including walking and cycling; 
More community engagements by concentrating on local sectors, creating more linkages between users and visitors and encouraging visitors to explore other parts of the precinct;

- $\quad$ Additional data-based hubs, such as a smart health hub and an interactive environment of digital information on public transport and beach capacity.

Participants were also asked about the best smart city opportunities for the LL. Results included smart data analysis, public information systems, data-driven community participation, sharing of data, smart parking, an innovation ecosystem or the measurement of movement (Afrooz et al. 2018a). Participants mentioned key datasets which were required to design, implement and monitor the performance of the Randwick LL as both 2D and 3D geospatial data including point cloud data, BIM models, and mobility data comprising current and projected movement patterns and journey times. They mentioned a need for a wider community engagement and participation.

Using the outcomes from part 1 the sketch planning session as a basis, participants were asked to consider potential initiatives, measures of success, stakeholders and project partners that could play a role in implementing the visions for the 5 key themes in part 2. These outcomes have been described in detail in (Afrooz et al. 2018a). Part 2 provided insights on how to implement the LL concept by exploring partnership opportunities between stakeholders in the precinct. The residents, local businesses, Randwick City Council, UNSW, and the Prince of Wales Hospital were consistently identified as the main stakeholders. It was suggested to establish a formal working group composed of representatives from the stakeholder groups. Furthermore, an initiative that specifically aimed to activate community engagement was proposed.

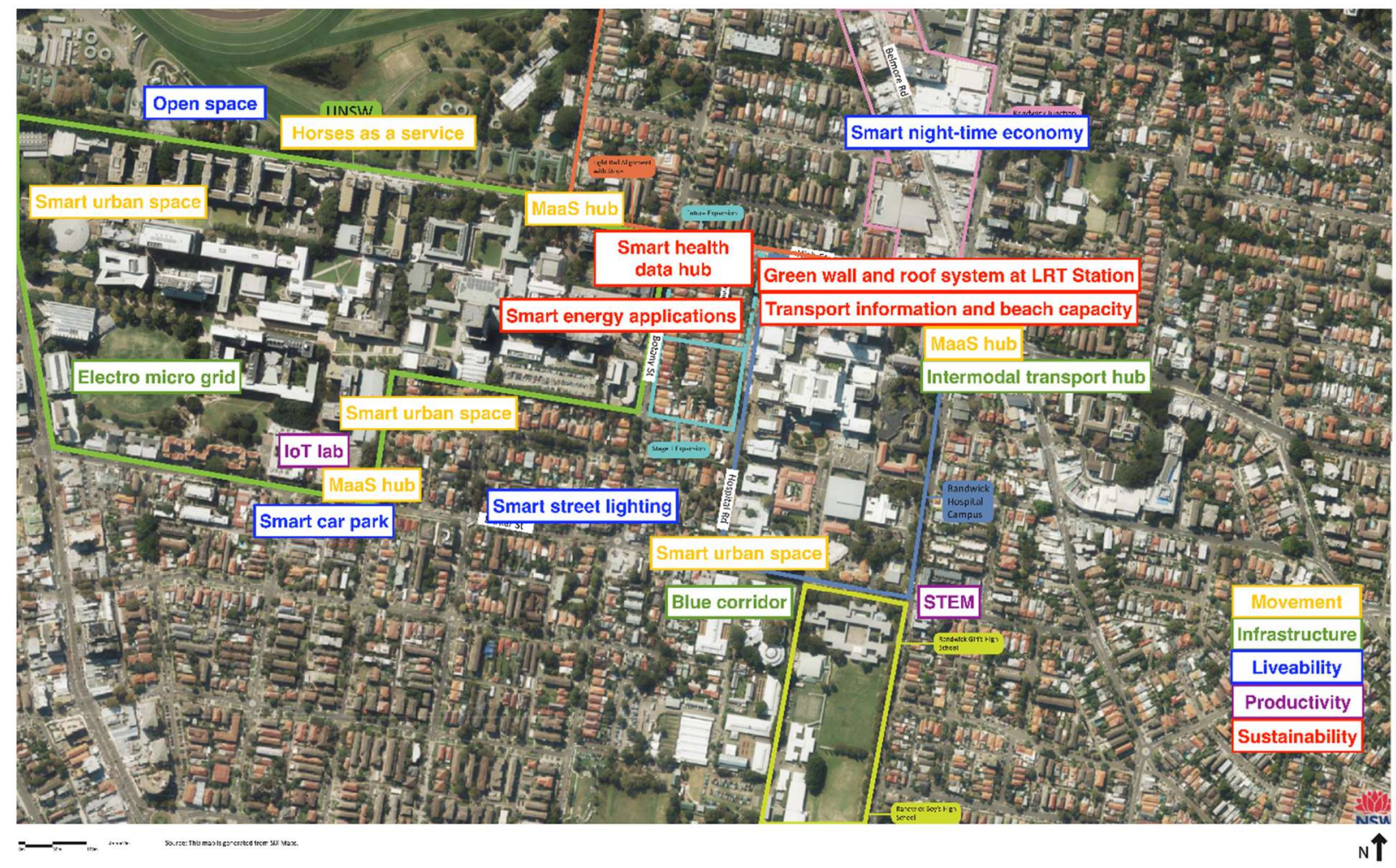

Figure 3 Participants' idea for the five themes captures through a sketch planning exercise undertaken in the City Analytics Lab (Afrooz et al. 2018a)

\section{EVALUATION RESULTS}

Based on the results of the usability evaluation survey, we found that the CAL at UNSW and especially the interactive multi-touch tables were seen as beneficial to the creation of a LL environment which enabled participants to collaboratively sketch plan and design ideas using interactive maps, digital post-it notes and other digital planning tools. Participants were able to swipe and share digital artefacts between interactive tables using the Cruiser software functionality. This unique technology enabled a high level of collaborations both within and between thematic groups and between user and technology.
Although, the use of sketch planning and interactive tables in LLs is a relatively new concept, most participants found the interactive cruiser tables useful in supporting the Randwick precinct LL. For example, the survey showed that most respondents preferred to sketch their designs on the interactive table rather than on paper $(58,1 \%$ compared to $32,3 \%)$. Additionally, respondents reacted positively to the ability to share digital artefacts between tables. They praised the interactive sharing, the ease to share data with other teams and the collaborative nature of the lap.

Despite receiving positive responses to the integration of interactive tables with the LL, the survey showed some drawbacks to the interactive screens. The primary problem was 
writing on the screen which was a slow process for participants. In addition, linking the texts to the map, correcting mistakes, and drawing straight lines on maps were difficult for most participants. These results were in line with findings previously found in evaluating the effectiveness of the CAL (Punt et al. 2020). However, despite the abovementioned problems, participants found the tables and other digital technology tools at CAL beneficial in supporting interactions, discussions, information gathering and multitasking during the workshop.

The results from part 1 and part 2 of the LL particularly reflect the participatory and user-centric design approaches of LL design found in the literature (Almirall and Wareham 2011; Franz et al. 2015). Based on the feedback from participants, we argue that the CAL can provide unique support for LL, because it provided a collaborative space where actors can come together to interact with each other and formulate and explore current and future urban environments as support through a suite of data driven smart city planning tools. The setting of CAL promotes engagement and collaboration and provides connectivity through both the interactions between technology-to-people and peopleto-people (Punt et al. 2020).

We compared the case study with the common approaches to user-centric LLs in the literature and found that the Randwick LL matched user-centric and participatory design approaches. In particular, the case study took a similar approach to the Robust's (2019b) study that took a participatory co-design approach to the co-creation of a vision for the Lisbon Metropolitan Area as well as Dupont et al. (2016) who looked at the role of digitally immersive spaces. However, our LL somewhat advanced this concept by applying a suite of digital sketch planning tools, including the use of data visualisation, interactive dashboards and multi-touch tables. Previous studies have not addressed the role of these digital tools in improving user-to-technology interactions and group collaborations. Participants were encouraged to engage and participate in the process of the LL which resulted in valuable outcomes. The innovation process at Randwick precinct LL was based on human needs and participants quickly learned how to use the multitouch tables and other data driven tools in the CAL. In addition, participants were encouraged to codesign the Randwick precinct. Therefore, this case study fits within the user-centred and participatory design approaches to LLs, whilst benefiting from the advancements of smart city planning technology.

Overall, the Randwick precinct LL has led to a better understanding of how to make the LL concept operate at a precinct level and what future directions the Randwick precinct LL might entail. The LL was a collaborative platform which supported user-centric data driven innovation. This is in line with user-centred and participatory approaches to the LL found in the literature with technology advancements made possible through the digital tools within the City Analytics Lab.

\section{CONCLUSION}

In this study, we described the outcomes of a LL case study where like-minded people from a diversity of disciplines gathered in an equipped co-design laboratory and digitally immersive space City Analytics Lab - to participate in the design of the Randwick precinct.

In the Randwick precinct LL, we focused on realism, and usercentric and data-driven approaches which included four core principles of LL including empowerment of users, openness, innovation, and realism. Additionally, this case study also contributes to the innovative aspect of LL, through the enhancement of digital collaboration by using the multitouch tables.
Randwick precinct LL provided different learning and collaborative opportunities for the participants through a series of presentations, interactive sketch planning and ideation sessions where participants could share knowledge and collaborate in shaping the future of the Randwick smart precinct. In summary, the Randwick precinct LL contributed to inclusiveness, collaboration and consensus building. However, future LL events in the precinct should include the direct involvement of the local citizens and students who live and interact in the Randwick precinct. The involvement of all key stakeholder groups is an essential ingredient for LL events while this can be sometimes challenging in the real world. In the long-term it is important to hold a continued conversation between users and developers in the LL in order to improve the collaboration between different stakeholders and to match the digital tools to the needs of the users. This requires time and effort and involves facilitating conversations and finding common ground.

\section{ACKNOWLEDGEMENTS}

The authors would like to acknowledge the support from the CRC Low Carbon Living for funding the Randwick precinct Living Lab workshop.

\section{REFERENCES}

Publication bibliography

Afrooz, A.; Punt, E.; Ticzon, C.; Agagiotis, S.; Jacobs, R.; Summerhayes, S.; Pettit, C. (2018a): Precinct scale living laboratories and the value of spatial data. With assistance of Low Carbon Living CRC, CityFutures, UNSW, Randwick City Council. Australian Government, Department of Industry, Innovation and Science. Available online at https://www.citiesleadership.com/post/precinct-scale-livinglaboratories-and-the-value-of-spatial-data, checked on 5/3/2020. Afrooz, Aida; Ballal, H.; Pettit, C. (2018b): Implementing augmented reality sandbox in geodesign: a future. In : ISPRS 2018: 3D Special information science-the engine of change: Proceedings of the ISPRS TC IV Mid-term Symposium part fo the ISPRS Annals of the Photogrammetry, Remote Sensing and Spatial Information Sciences. Copernicus Publications, pp. 512.

Almirall, Esteve; Wareham, Jonathan (2011): Living Labs: arbiters of mid-and ground-level innovation. In Technology Analysis \& Strategic Management 23 (1), pp. 87-102.

Bergvall-Kareborn, Birgitta; Stahlbrost, Anna (2009): Living Lab: an open and citizen-centric approach for innovation. new ROBUST tools for better regional policymaking, p. 356. DOI: 10.1504/IJIRD.2009.022727.

Chronéer, Diana; Ståhlbröst, Anna; Habibipour, Abdolrasoul (2019): Urban living labs: Towards an integrated understanding of their key components. In Technology Innovation Management Review 9 (3), pp. 50-62.

Corelabs (2007): Living Labs Roadmap 2007-2010.

Recommendations on Networked Systems for Open UserDriven Research, Development and Innovation. Centrum for Distance Spanning Technology, Luleå University of Technology. Available online at https://www.scribd.com/document/38953413/Living-LabsRoadmap-2007-2010, checked on 2/20/2020.

Cosgrave, Ellie; Arbuthnot, Kate; Tryfonas, Theo (2013):

Living labs, innovation districts and information marketplaces: A systems approach for smart cities. In Procedia Computer Science 16, pp. 668-677. 
Cruiser Interactive (2019): Cruiser Interactive homepage. Available online at https://www.cruiserinteractive.com.au/, checked on $7 / 14 / 2020$.

Dell'Era, Claudio; Landoni, Paolo (2014): Living Lab: A Methodology between User-Centred Design and Participatory Design. In Creativity and Innovation Management 23 (2), pp. 137-154. DOI: 10.1111/caim.12061.

Dourish, Paul (2003): The Appropriation of Interactive Technologies: Some Lessons from Placeless Documents. In Computer Supported Cooperative Work (CSCW) 12 (4), pp. 465-490. DOI: 10.1023/A:1026149119426.

Dupont, Laurent; Morel, Laure; Pallot, Marc (2016): Exploring the Appropriateness of Different Immersive Environments in the Context of an Innovation Process for Smart-Cities. In : 2016 International Conference on Engineering, Technology and Innovation/IEEE International Technology Management Conference (ICE/ITMC). Ieee, pp. 1-9.

Dupont, Laurent; Pallot, Marc; Christmann, Olivier; Morel, Laure; Boly, Vincent; Richir, Simon (2017): Exploring mixedmethods instruments for performance evaluation of immersive collaborative environments.

Eriksson, M., V.P. Niitamo, and S. Kulkki (2005): State-of-theart in Utilizing Living Labs Approach to User-centric ICT innovation - a European approach. Centre of Distance Spanning Technology, Luleå University of Technology, Sweden, Nokia Oy, Centre for Knowledge and Innovation Research at Helsinki School of Economics, Finland. Available online at https://www.researchgate.net/publication/272566632_Living_la bs_as_a_multi-contextual_RD_methodology, checked on $2 / \overline{2} 0 / \overline{2} 0 \overline{2} 0$.

Finnigan, S.M., Clear, A.K. (2018): What are your thoughts on this place? A novel approach to Living Lab engagement and evaluation. In Chi (Ed.): Living labs. Measuring Human Experience in the Built Environment. CHI'18 Workshop. Montreal, Canada, April 222018.

Franz, Yvonne; Tausz, Karin; Thiel, Sarah-Kristin (2015): Contextuality and co-creation matter: A qualitative case study comparison of living lab concepts in urban research. In Technology Innovation Management Review 5 (12). Goodspeed, Robert; Pelzer, Peter; Pettit, Christopher (2017): The Role Computer Technologies Can Play. In Planning knowledge and research, p. 139.

Harrison, Helena; Birks, Melanie; Franklin, Richard; Mills, Jane (2017): Case study research: Foundations and methodological orientations. In : Forum Qualitative Sozialforschung/Forum: Qualitative Social Research, vol. 18.

Karaseva, Victoria; Seffah, Ahmed; Porras, Jari (2015): A social-media-based living lab: an incubator for human-centric software engineering and innovation. In : Proceedings of the 2015 International Conference on Software and System Process, pp. 194-198.

Knight-Davidson, Pamela; Lane, Pauline; McVicar, Andrew (2020): Methods for co-creating with older adults in living laboratories: a scoping review. In Health and Technology, pp. 1-13.

Leminen, Seppo; Niitamo, Veli-Pekka; Westerlund, Mika (2017): A Brief History of Living Labs: From Scattered Initiatives to Global Movement. In : Research Day Conference proceedings 2017, p. 42.

Liamputtong, P. (2011): Focus Group Methodology:

Introduction and History. In Pranee Liamputtong (Ed.): Focus Group Methodology: Principles and Practice. 1 Oliver's Yard, 55 City Road, London EC1Y 1SP United Kingdom: SAGE Publications Ltd, pp. 1-14.

Lieske, Scott N.; van den Nouwelant, Ryan; Han, Jung Hoon; Pettit, Christopher (2019): A novel hedonic price modelling approach for estimating the impact of transportation infrastructure on property prices. In Urban Studies, 0042098019879382.

Park, Giyoung; Nanda, Upali; Zakrzewski, Tommy; Gray, Whitney Austin (2018): The Living Labs: Data-Driven Research and Wellbeing. HKS, Inc. Available online at https://www.hksinc.com/our-news/articles/taking-measure-ofthe-living-lab/, checked on 5/6/2020.

Pettit, Christopher; Hawken, Scott; Ticzon, Carmela; Nakanishi, Hitomi (2019a): Geodesign-A Tale of Three Cities. In :

International Conference on Computers in Urban Planning and Urban Management. Springer, pp. 139-161.

Pettit, Christopher; Lieske, Scott N.; Jamal, Murad (2017a): CityDash: Visualising a changing city using Open Data. In : International Conference on Computers in Urban Planning and Urban Management. Springer, pp. 337-353.

Pettit, Christopher; Tice, Andrew; Randolph, Bill (2017b): Using an online spatial analytics workbench for understanding housing affordability in Sydney. In : Seeing Cities Through Big Data: Springer, pp. 233-255.

Pettit, Christopher J.; Hawken, Scott; Ticzon, Carmela; Leao, Simone Z.; Afrooz, Aida E.; Lieske, Scott N. et al. (2019b): Breaking down the silos through geodesign-Envisioning Sydney's urban future. In Environment and Planning B: Urban Analytics and City Science 46 (8), pp. 1387-1404.

Punt, E. P.; Geertman, S. C.M.; Afrooz, A. E.; Witte, P. A.; Pettit, C. J. (2020): Life is a scene and we are the actors: Assessing the usefulness of planning support theatres for smart city planning. In Computers, Environment and Urban Systems 82, p. 101485

Robust (2019a): Lisbon Live Case 3. Knowledge Sharing and Networking for Open Innovation. Available online at https://rural-urban.eu/living-lab/lisbon/live-cases, checked on 3/3/2020.

Robust (2019b): Lisbon Living Lab held its first working session with local stakeholders. Available online at https://ruralurban.eu/news/lisbon-living-lab-held-its-first-working-sessionlocal-stakeholders, checked on 3/3/2020.

Robust (2019c): Spatial analysis. new ROBUST tools for better regional policymaking. Available online at https://ruralurban.eu/news/spatial-analysis-new-robust-tools-betterregional-policymaking, checked on 3/3/2020.

Romero Herrera, Natalia (2017): The Emergence of Living Lab Methods. In David V. Keyson, Olivia Guerra-Santin, Dan Lockton (Eds.): Living Labs, vol. 22. Cham: Springer International Publishing, pp. 9-22.

Schaffers, H.; Cordoba, M. G.; Hongisto, P.; Kallai, T.; Merz, C.; van Rensburg, J. (Eds.) (2007): Exploring business models for open innovation in rural living labs. 13th International Conference on Concurrent Enterprising. Sophia-Antipolis, France, 4-6 June.

Schuurman, D.; Coorevits, L.; Logghe, S.; Vandenbroucke, K.; Georges, A.; and Baccarne, B. (2015): Co-creation in living labs. exploring the role of user characteristics on innovation contribution. In Services Sciences 5 (3/4).

Veeckman, Carina; van der Graaf, Shenja (2015): The city as living laboratory: Empowering citizens with the citadel toolkit. In Technology Innovation Management Review 5 (3).

Vonk, Guido; Ligtenberg, Arend (2010): Socio-technical PSS development to improve functionality and usability — Sketch planning using a Maptable. In Landscape and Urban Planning 94 (3-4), pp. 166-174.

Voytenko, Yuliya; McCormick, Kes; Evans, James; Schliwa, Gabriele (2016): Urban living labs for sustainability and low carbon cities in Europe: towards a research agenda. In Journal of Cleaner Production 123, pp. 45-54. DOI:

10.1016/j.jclepro.2015.08.053. 